\title{
On the Rate of Formation of Steroidal Glucuronosides in Patients with Familial and Acquired Jaundice *
}

\author{
William D. Drucker, $\nmid$ Anastasia Sfikakis, $\ddagger$ Abraham J. Borkowski, $\S$ and \\ Nicholas P. Christy WITh The TEChNiCAL aSSistance of \\ AnNAMARIE L. VERDE \\ (From the Department of Medicine, Columbia University College of Physicians \& Surgeons, \\ and the Presbyterian Hospital, New York, N. Y.)
}

The inactivation and excretion of many lipidsoluble compounds is a result of metabolic transformation to more polar substances (1). For cortisol, ${ }^{1}$ this is sequentially accomplished in man by reduction of the 4,5 double bond in ring $A$ to yield "dihydro" derivatives, then reduction of the ketone group at carbon three to yield "tetrahydro" compounds (2). Reduction of the C-20 ketone group to a hydroxyl leads to further increase in polarity (3). Once formed, these reduced compounds are rendered still more water-soluble by conjugation at the three position with glucuronic acid $(1,4)$. The formation of such glucuronosides also results in a lesser degree of binding to plasma proteins $(5,6)$.

The conjugation of a substrate with glucuronic acid in ester or glycosidic linkage requires uridine

\footnotetext{
* Submitted for publication October 9, 1963; accepted June 22, 1964.

Supported by grant AM-04035 from the National Institutes of Health and by the Health Research Council of the City of New York under contract U-1088.

†This investigation was carried out during the tenure of a postdoctoral fellowship from the National Heart Institute. Currently, Career Scientist, Health Research Council, City of New York. Present address: Department of Medicine, New York University School of Medicine, New York, N. Y.

$¥$ Present address : 2 Stisikourou Street, Athens, Greece. $\S$ Present address: Institut Jules Bordet, Brussels, Belgium.

${ }^{1}$ The following trivial names and abbreviations have been employed: cortisol $(11 \beta, 17 \alpha, 21$-trihydroxy-4-pregnene-3,20-dione) ; cortisone (17 $\alpha, 21$-dihydroxy-4-pregnene3,11,20-trione); dihydrocortisol (11 $\beta, 17 \alpha, 21$-trihydroxypregnane-3,20-dione) ; dihydrocortisone (17 $\alpha, 21$-dihydroxy-

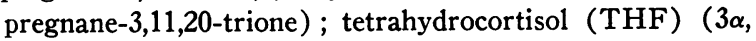
$11 \beta, 17 \alpha, 21$-tetrahydroxy-pregnane-20-one) ; allotetrahydrocortisol (allo-THF) $\quad(3 \alpha, 11 \beta, 17 \alpha, 21$-tetrahydroxy-allopregnane-20-one) ; tetrahydrocortisone (THE) $(3 \alpha, 17 \alpha$, 21 -trihydroxy-pregnane-11,20-dione); $6 \beta$-hydroxycortisol $(6 \beta, 11 \beta, 17 \alpha, 21$-tetrahydroxy-4-pregnene-3,20-dione).
}

diphosphate-glucuronic acid (UDPGA) and the microsomal enzyme, uridine diphosphate (UDP)transglucuronylase (7). These requirements were demonstrated for a reduced steroid by Isselbacher and Axelrod $(8,9)$, who isolated tetrahydrocortisone glucuronoside after incubation of THE and UDPGA with guinea pig liver microsomes.

Bilirubin also requires conjugation with glucuronic acid for its normal excretion into the bile $(10,11)$. In children with the Crigler-Najjar syndrome (12), extreme retention of unconjugated bilirubin with kernicterus, two studies of steroid metabolism $(13,14)$ have shown a delay in the formation of THE-glucuronoside after the intravenous administration of THE. Although ability to form this steroidal glucuronoside was not entirely abolished, its total synthesis was decreased.

In 1957, Arias and London (15) showed that hepatic deficiency of UDP-transglucuronylase accounted for certain instances of mild jaundice associated with chronic retention of unconjugated bilirubin in adults. Further studies have confirmed this conclusion (16). The present investigation was undertaken to elucidate the qualitative and quantitative aspects of steroid glucuro-conjugation in these patients and in others with familial and acquired jaundice.

\section{Methods}

Patients. Twelve healthy, ambulatory adults, $6 \mathrm{fe}-$ male and 6 male, served as controls for measurement of the disappearance rate of steroids from plasma. Three of these subjects were further studied for their urinary excretion of steroids. Two patients with untreated Addison's disease were studied in order to discover whether prolonged absence of steroid substrate brings about abnormalities in hepatic enzymes concerned with steroid metabolism. Neither of these individuals had ever been jaundiced. Four patients with chronic unconjugated hy- 
perbilirubinemia (three with hepatic deficiency of UDPtransglucuronylase and one with congenital hemolytic icterus) and two patients with the Dubin-Johnson syndrome (17) made up the group with familial jaundice (Table I). ${ }^{2}$ Except for elevated levels of serum bilirubin, studies of hepatic function yielded normal results in all of these patients. Only the two patients with DubinJohnson syndrome demonstrated retention of sulfobromophthalein. By light microscopy, liver biopsy specimens obtained from five of the six patients were normal except for the finding of the characteristic pigment in the parenchymal liver cells of the patients with DubinJohnson syndrome. Further clinical data concerning these subjects are summarized in Table I. One patient with a past history of both acute viral hepatitis and hepatitis associated with infectious mononucleosis who was later found to have unconjugated hyperbilirubinemia and two patients with Laënnec's cirrhosis were also studied; pertinent data are presented in Table II. The patients with hepatic diseases other than UDP-transglucuronylase deficiency were studied to determine whether the lesion present in the latter group was specific.

Administration of steroids. Crystalline tetrahydrocortisone, ${ }^{3} 75 \mathrm{mg}$ and $225 \mathrm{mg}$, was dissolved in $5 \mathrm{ml}$ of hot distilled $95 \%$ ethanol and added to an infusion bottle containing $100 \mathrm{ml}$ of warm, sterile, normal saline. To insure complete transfer, the beaker used for dissolving the steroid was rinsed 3 times with $2 \mathrm{ml}$ of hot ethanol, and the rinses were added to the saline. Cortisol was drained directly from a vial containing $100 \mathrm{mg}$ of cortisol in alcoholic solution into an infusion bottle containing $100 \mathrm{ml}$ of normal sterile saline and used without further manipulation for intravenous administration. In one patient with UDP transglucuronylase deficiency and in the patient with a past history of hepatitis, an attempt was made to inhibit the glucuroconjugation of administered steroid by the simultaneous oral administration of a compound (menthol) that is also normally excreted in large part as a glucuronoside $(1,16)$.

The THE injected and the steroid standards, THE, $\mathrm{THF}$, and cortisol used in subsequent analyses were tested for purity. The compounds gave single spots by blue tetrazolium staining or ultraviolet absorption and had typical $R_{\mathfrak{r}}$ values when chromatographed in the Bush $B_{5}(20)$ and $E_{2} B$ (21) systems. They also gave infrared spectra 4 identical to authentic standards.

${ }^{2} \mathrm{We}$ are indebted to Dr. Irwin Arias, Department of Medicine, Albert Einstein College of Medicine, for referring the patients with hepatic glucuronyl transferase deficiency and the Dubin-Johnson syndrome to us for study. His permission to use the data collected by him in this paper and his unfailing co-operation are deeply appreciated.

${ }^{3}$ We express our gratitude to Dr. Karl Pfister of Merck and Co., Rahway, N. J., for the generous supply of tetrahydrocortisone, tetrahydrocortisol, and cortisol.

$4 \mathrm{Mr}$. Otto Gonzales kindly carried out the analyses in the laboratory of Dr. Seymour Lieberman.

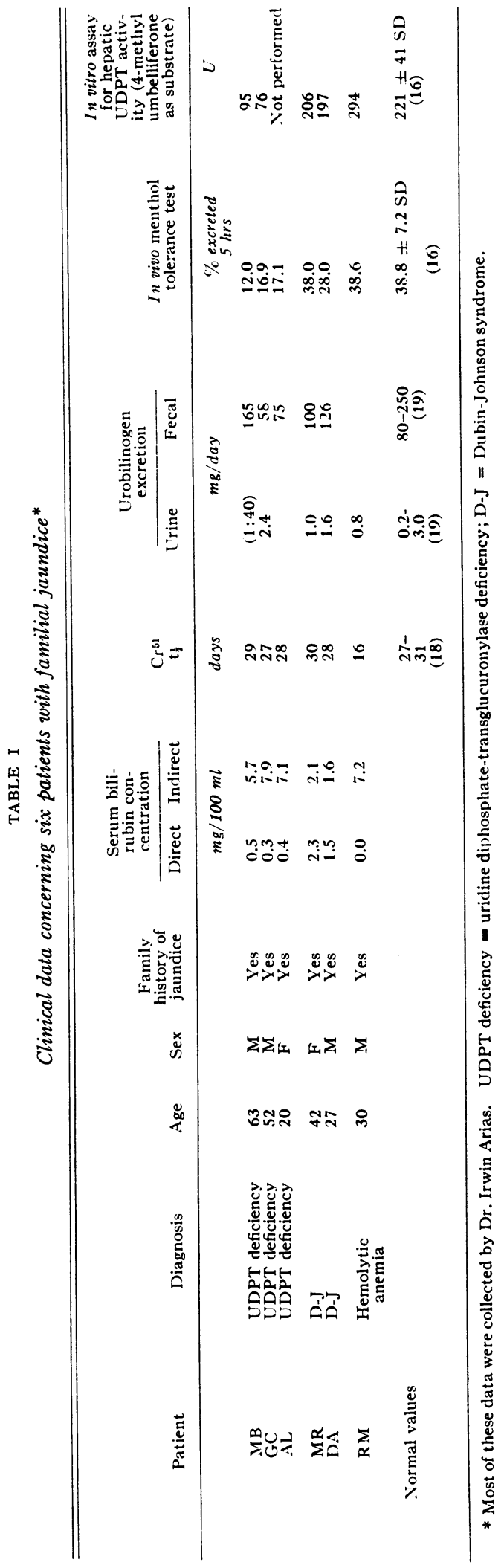




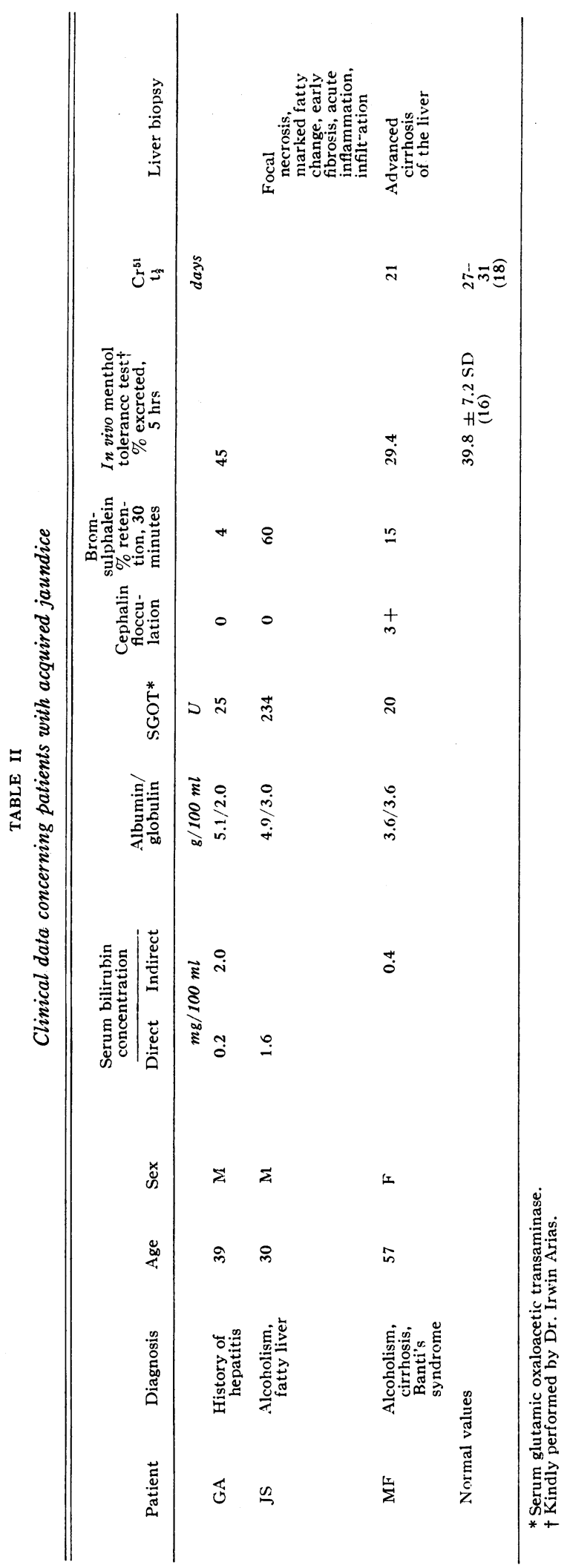

Rate of disappearance of steroids from plasma. Solutions containing steroids were given within 15 minutes after mixing; solutions were rapidly infused into an antecubital vein of all subjects immediately after the removal of $15 \mathrm{ml}$ of blood that was used for the determination of basal plasma level of cortisol. All infusions were begun between 9 and 10 a.m. and were completed in 5 to 8 minutes. The mid-point of infusion was used as zero time. After administration of THE, venous blood was obtained by repeated venipuncture or indwelling needle at $20,30,45$, and 60 minutes from zero time; for cortisol, the time schedule was $45,60,90$, and 120 minutes. Samples were immediately transferred to heparinized tubes and centrifuged within 30 minutes. Plasmas not assayed immediately were quickly frozen and stored at $-20^{\circ} \mathrm{C}$ until used. Two- or 3-ml samples of plasma were used for the determination of plasma 17-hydroxycorticosteroid level by the Silber-Porter method (22), as modified by Peterson, Karrer, and Guerra (23) and in this laboratory (24) with cortisol as standard. Samples from any one experiment were tested simultaneously. Duplicate determinations were frequently made and showed a variability of less than $10 \%$.

Disappearance rate from plasma was determined by plotting the four steroid values obtained against time on semilogarithmic paper. The best straight line through all points was found by applying the method of least squares. Plasma disappearance rate was then determined by extrapolating this line to the $y$-axis (zero time). The plasma disappearance rate is expressed as the biologic half-time $\left(t_{\frac{1}{2}}\right) .^{5}$ For THE, the standard amount given was $75 \mathrm{mg}$; in a few instances $225 \mathrm{mg}$ was given to provide a further overloading of hepatic detoxication mechanisms in an effort to detect subtle abnormalities.

Collection of urine. In all but two subjects, 24-hour urine specimens were obtained before infusion of steroid. These were started between 7 and 9 a.m. and were usually collected in two 4-hour samples for the first 8 hours and in two 8-hour samples for the remaining 16 hours. Urine specimens were collected in a similar manner after infusion of steroid except that on most occasions 1-hour samples were obtained for the first 4 hours to preclude masking of early abnormalities in steroid metabolism. All urines were kept refrigerated during collection and were frozen as quickly as possible thereafter unless immediately processed. No preservatives were used.

Determination of free steroids in urine. Each sample of urine was adjusted to $\mathrm{pH} 4.5$ with glacial acetic acid and extracted twice with double volumes of distilled ethyl acetate. The combined ethyl acetate extracts were washed 3 times with 0.05 volume of saturated sodium carbonate and 3 times with 0.05 volume of distilled water. They were then acidified with one or two drops of glacial acetic acid and dried over small amounts of anhydrous

5 For the purpose of this study, the question whether the disappearance curve is a single or multiple exponential is ignored. 
sodium sulfate. The clear ethyl acetate extracts were then concentrated under vacuum at $37^{\circ} \mathrm{C}$ with a flash evaporator. In a few instances, a sample of urine was set aside for the determination of its $6 \beta-\mathrm{OH}$-cortisol content. The previously published methods of Frantz, Katz, and Jailer (25) were employed for the extraction and quantification of this steroid using added $4-\mathrm{C}^{14}$-cortisol to correct for losses in extraction and paper chromatography.

Determination of glucuronic acid conjugates in urine. The urine remaining after extraction was incubated at $37^{\circ} \mathrm{C}$ and $\mathrm{pH} 4.5$ for 5 days with $\beta$-glucuronidase, ${ }^{6} 300$ Fishman $U$ per $\mathrm{ml}$ of urine. The urine was then extracted and processed as described above for the recovery of the free steroids. To assess the recovery of steroid after the hydrolysis, extraction, and washing and concentrating procedures, cortisol-4- $\mathrm{C}^{14}$ of known specific activity was added to several samples of urine and treated in the same manner as the unknowns. Radioactivity was assayed in a liquid scintillation spectrometer; ${ }^{7}$ efficiency for carbon ${ }^{14}$ was $54 \%$. Recovery of radioactivity from the urine so treated averaged $87 \%$. No corrections for these losses have been made in the final calculations. The term "glucuronoside" is used throughout to mean steroid measured after hydrolysis with $\beta$-glucuronidase.

Samples of the extracts were prepared for paper chromatography in such a way as to contain from 10 to 100 $\mu \mathrm{g}$ of steroid. The samples were made from a solution of the concentrated extracts dissolved in dichloromethane: methanol, 2:1, and were dried under a stream of nitrogen. Samples were concentrated in the bottom of each tube, dissolved in 4 drops of the dichloromethane: methanol mixture, and quantitatively applied with a polished capillary pipette, to 1 -inch strips of Whatman $3 \mathrm{MM}$ chromatography paper by streaking along a narrow band penciled onto the paper. The greatest care was taken to distribute the sample evenly across the paper. Several rinses of the tube were applied to the chromatogram. With every four unknowns, two 1-inch strips containing $20-\mu \mathrm{g}$ amounts each of THE, THF, and cortisol were prepared in like manner. The chromatograms were equilibrated for 2 to 3 hours in the Bush $B_{5}$ system and developed overnight for a total of 18 hours. After the strips were dried, at room temperature, they were viewed under ultraviolet light and then cut exactly in half. The left half of each strip was stained with an alkaline solution of blue tetrazolium and the THE, THF, and cortisol areas were identified by comparison with stained halves of the standard strips. Not infrequently, the urine samples ran at a somewhat slower rate than the standards, demonstrating the need to compare each unknown with itself to determine accurately the position of each steroid on the paper. Blue tetrazolium spots more polar (closer to the origin) than THF were not considered further in this experiment. Frequently, a seemingly discrete blue tetrazolium, Porter-Silber positive spot,

\footnotetext{
6 Ketodase, Warner-Chilcott Laboratories, Morris Plains, N. J.

${ }^{7}$ Packard Instrument Co., La Grange, Ill.
}

running between THF and THE consistent with alloTHF was also seen. If this allo-THF area was rechromatographed separately in the Bush $\mathrm{B}_{5}$ or $\mathrm{E}_{2} \mathrm{~B}$ systems, it usually showed the presence of some THE but no THF. The THF area remained homogenous on subsequent rechromatography, but the THE spot usually could be shown to contain allo-THF as a minor component. Apparently, after one chromatographic step in the Bush $\mathrm{B}_{5}$ system, with many hours of overrunning, THF can be cleanly separated from allo-THF if the paper is not overloaded with steroid. The separation of allo-THF from THE is less reliably achieved even when blue tetrazolium staining seems to indicate the presence of discrete spots. Since by our method of quantification, allo-THF is probably underestimated by $66 \%$ when THE is used as standard (26), the lower portion of any alloTHF spot seen was eluted along with the discernible THE area and subsequently treated as THE. Any error from this maneuver should be insignificant because after THE administration no interconversion to alloTHF is known to take place (27), and the values for THE (contaminated with allo-THF) and THF in control urine samples have been subtracted from those observed after THE administration, a procedure that tends to cancel out completely the endogenous contribution of allo-THF to the estimation of THE. This procedure also prevents the risk of losing THE by demarcating the THE area too sharply and arbitrarily from that of allo-THF.

The appropriate areas on the unstained standard and unknown strips were eluted by suspending one corner of each paper on a bent no. 22 hypodermic needle and allowing $10 \mathrm{ml}$ of dichloromethane: methanol, 2:1, to drip slowly through a syringe attached to the needle. When dry, the paper was rotated twice and eluted each time with $10 \mathrm{ml}$ of solvent. This technique allowed quantitative elution of the steroids as determined by absence of blue tetrazolium staining on the eluted strips and absence of Porter-Silber chromogens in further exhaustive elutions. All the eluates were dried under nitrogen in a water bath at $37^{\circ} \mathrm{C}$.

The dried eluates of the unknowns and standards and a blank tube were next shaken with $25 \mathrm{ml}$ of dichloromethane and washed twice with $4 \mathrm{ml}$ of $0.1 \mathrm{~N} \mathrm{NaOH}$. This washing procedure removed much chromogenic material. Two $10-\mathrm{ml}$ samples of the dichloromethane extracts were next pipetted into a centrifuge tube of $15-\mathrm{ml}$ capacity, which contained either $0.2 \mathrm{ml}$ blank reagent (11.2 $\mathrm{M} \mathrm{H}_{2} \mathrm{SO}_{4}$ : redistilled absolute ethanol, 2:1) or $0.2 \mathrm{ml}$ freshly prepared Porter-Silber reagent $(75 \mathrm{ml}$ blank reagent plus $32.5 \mathrm{mg}$ recrystallized phenylhydrazine hydrochloride). These were shaken and centrifuged, and the solvent was removed carefully by aspiration. Maximal color was allowed to develop by incubating the tubes overnight in the dark at room temperature. Fifteen hours later, the blanks were read in a Beckman DU spectrophotometer at $410 \mathrm{~m} \mu$; the tubes containing the reagent were also read at 370,410 , and $450 \mathrm{~m} \mu$ as if applying the Allen correction (28). Only reagent readings that had sharp absorption maxima at $410 \mathrm{~m} \mu$ were ac- 
cepted as representing steroidal material. Blank readings at $410 \mathrm{~m} \mu$ were usually much less than $25 \%$ of the reagent reading at this wave length. The THF standard was used to quantify the THF unknowns because of the observed lesser chromogenicity of THF in the PorterSilber reaction $(26,29)$. THE and cortisol standards were used to quantify THE and cortisol unknowns, respectively, although the latter two proved to be interchangeable $(23,26)$. The quantity of steroid on each strip was calculated by reference to the optical density of the chromatographed standard. To obtain the content of steroid in the original extracts, the steroid content on paper was multiplied by the dilution factor of the sample.

This procedure for quantification automatically corrects all systematic losses, since the standards were handled in the same manner as the unknowns. By running a separate cortisol standard through the PorterSilber reaction simultaneously with each cortisol standard eluted off paper, it was determined that an average loss of $15 \%$ (range, 0 to $30 \%$ ) was incurred during the various paper chromatographic steps. For THE, the reproducibility of the method determined by running many duplicate samples averaged $\pm 15 \%$; for $\mathrm{THF}$, it averaged $\pm 20 \%$. Any value that appeared abnormal compared to the findings in normal subjects was rechecked. If it fell within the above limits, it was averaged with the initial value; if it was not within these limits, it was repeated at least twice until consistent results were obtained. Most inconsistencies were owing to improper selection of the sample (i.e., taking too small or too great an amount of steroid for optimal paper chromatography). Any value found to be less than $10 \mu \mathrm{g}$ per extract is reported as zero in order to eliminate the possibility that some minor nonspecific chromogen might be interpreted as representing true steroid content. All values are reported to the nearest hundredth of a milligram.

\section{Results}

\section{Rate of disappearance $\left(t_{\frac{1}{2}}\right)$ of infused THE and cortisol from plasma}

The rate of disappearance of infused steroid from the plasma of the ten patients and of eight normal subjects is shown in Table III. After administration of $75 \mathrm{mg}$ THE, the average $t_{\frac{1}{2}}$ for the normal subjects was 32 minutes (range, 19 to 41 minutes). In two patients with untreated Addison's disease the $t_{\frac{1}{2}}$ of THE was in the normal range. THE, $225 \mathrm{mg}$, was given to normal subject FX; the $t_{\frac{1}{2}}$ was 23 minutes, a value not significantly greater than for the 75-mg dose (19 minutes). In patients $\mathrm{MB}$ and $\mathrm{GC}$, both with UDP-transglucuronylase deficiency, the $t_{\frac{1}{2}}$ for 75 mg THE was prolonged (50 and 55 minutes). When this study was repeated in GC 1 year later and when oral menthol was given just before the

TABLE III

Rate of disappearance $\left(t_{3}\right)$ in minutes of infused tetrahydrocortisone and cortisol from plasma of normal subjects and patients

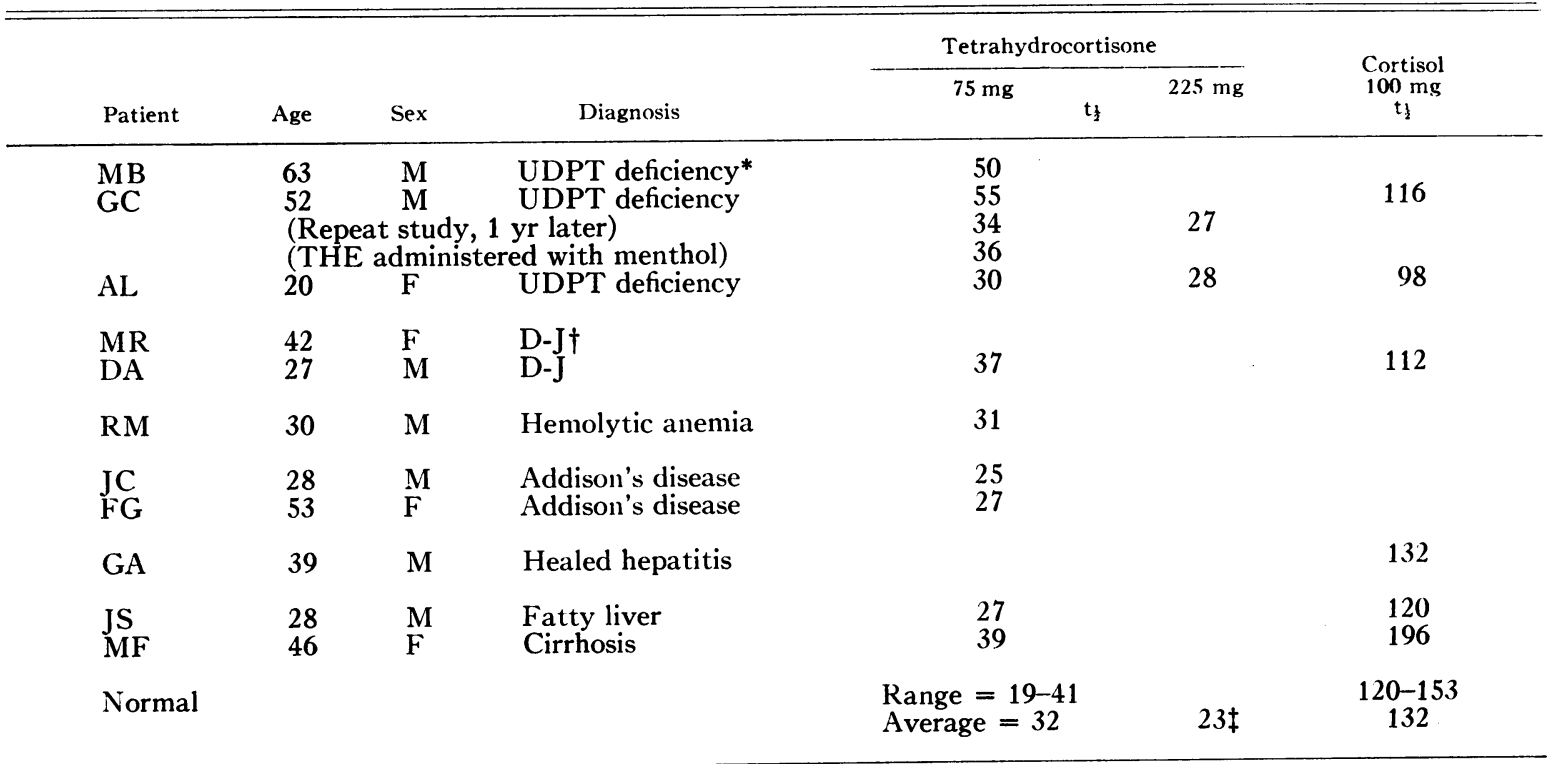

* UDPT deficiency = uridine diphosphate-transglucuronylase deficiency.

$\dagger \mathrm{D}-\mathrm{J}=$ Dubin-Johnson syndrome.

千 One normal subject, FX (M). 
infusion of steroid, the $t_{3}$ of THE was not increased. Normal values for plasma $t_{\frac{1}{2}}$ were found when $225 \mathrm{mg}$ of THE was administered intravenously to GC ( 1 year after original study with the lesser dose) and to $\mathrm{AL}$, another patient with UDP-transglucuronylase deficiency.

The rate of disappearance of cortisol, $100 \mathrm{mg}$, from plasma ranged from 120 to 153 minutes in the normal subjects and averaged 132 minutes (Table III). In two patients with UDP-transglucuronylase deficiency (GC and AL) and in one with the Dubin-Johnson syndrome (DA), the $t_{z}$ of cortisol was slightly shorter than in the normal subjects. No prolongation of plasma disappearance rate of cortisol was found in JS (fatty infiltration and necrosis of liver cells), but it was increased to 196 minutes in MF (advanced hepatic cirrhosis).

Steroid metabolites recovered in urine 24 hours after THE infusion

Normal subjects. One male (FX) and two females ( $A M$ and $M L$ ) received an infusion of THE, $75 \mathrm{mg}$. In a 24 -hour period, 41.0 to $58.7 \%$ of the infused steroid was recovered in the urine as THE and THF (Table IV). Of these metabolites, 1.0 to $1.5 \%$ was found as the free (unconjugated) steroid; the remainder was recovered in the glucuronoside (conjugated) fraction after $\beta$-glucuronidase hydrolysis. In control urine samples, the per cent unconjugated THE and THF ranged from 0.0 to 0.6 . Twenty-four hours after the administration of $225 \mathrm{mg}$ of THE to FX, $52.7 \%$ of the steroid was recovered in the urine as THE and THF. No percentage increase in the free fraction occurred after the higher dose : $1.2 \%$ unconjugated THE and THF was recovered after $225 \mathrm{mg}$ of THE vs. $1.5 \%$ after $75 \mathrm{mg}$ of THE (Table IV).

In all instances, increased quantities of THF were recovered after the administration of THE. Values of THF ranged from 3.0 to $8.5 \%$ of the total steroid recovered in a 24-hour urine sample. (These data are recorded for the first 4 hours of the collection period in Table V.) The interconversion of THE to THF was quite rapid; increased quantities of THF were excreted within the first hour (Table V). The process of interconversion continued, however, throughout the 24-hour period. Most of the urinary THE ap- peared as the glucuronoside. In FX, no greater quantity of THF was formed in the first 4 hours after $225 \mathrm{mg}$ of THE than after the lesser dose, although the excretion of THE approximately tripled (Table V). By the end of 24 hours, THF excretion was 1.65 times greater after the threefold larger dose of THE than after the lesser load, whereas THE excretion was 3.86 times greater.

Patients with familial jaundice. After both 75 $\mathrm{mg}$ and $225 \mathrm{mg}$ THE, the recovery of this steroid as urinary THE and THF over 24 hours was within the normal range (Table IV). In only one instance did the per cent excreted as unconjugated steroid exceed that of the normal subjects. At the same time that GC (the patient with UDP-transglucuronylase deficiency) received $75 \mathrm{mg}$ of $\mathrm{THE}$ and the $t_{\frac{1}{2}}$ of the steroid in plasma was prolonged (Table III), $14.2 \%$ of the recovered dose appeared as unconjugated metabolite, mainly THE. When, 1 year later $\mathrm{GC}$ was again given $75 \mathrm{mg}$ of THE, first alone and then 2 hours after $1 \mathrm{~g}$ of oral menthol, no increase in the per cent excretion of recovered metabolites as unconjugated THE was found. A greater loading dose (225 $\mathrm{mg} \mathrm{THE}$ ), given to GC and AL, produced no discernible abnormality in the 24-hour urinary excretion of metabolites. As in the one normal subject, total THF excretion was only slightly greater after the larger dose than after the smaller.

$\mathrm{MB}$, the other patient with UDP-transglucuronylase deficiency who had a prolonged $t_{\frac{1}{2}}$ of THE in plasma (Table III), did not excrete an increased percentage of the administered steroid in the unconjugated form; $97.8 \%$ of THE and THF recovered appeared in the glucuronoside fraction. Total recovery was $33.3 \%$ of the infused dose, a subnormal value. A somewhat greater percentage $(11 \%)$ of the administered THE was converted to THF, however.

No abnormalities in the metabolism of THE were noted in the patients with the Dubin-Johnson syndrome or in the patient with hemolytic jaundice (Table IV).

\section{Fractional excretion of urinary metabolites after THE infusion}

Normal subjects. In the three normal subjects, most of the recovered THE and THF, free and conjugated, appeared in the urine in the first 4 
W. D. DRUCKER, A. SFIKAKIS, A. J. BORKOWSKI, AND N. P. CHRISTY

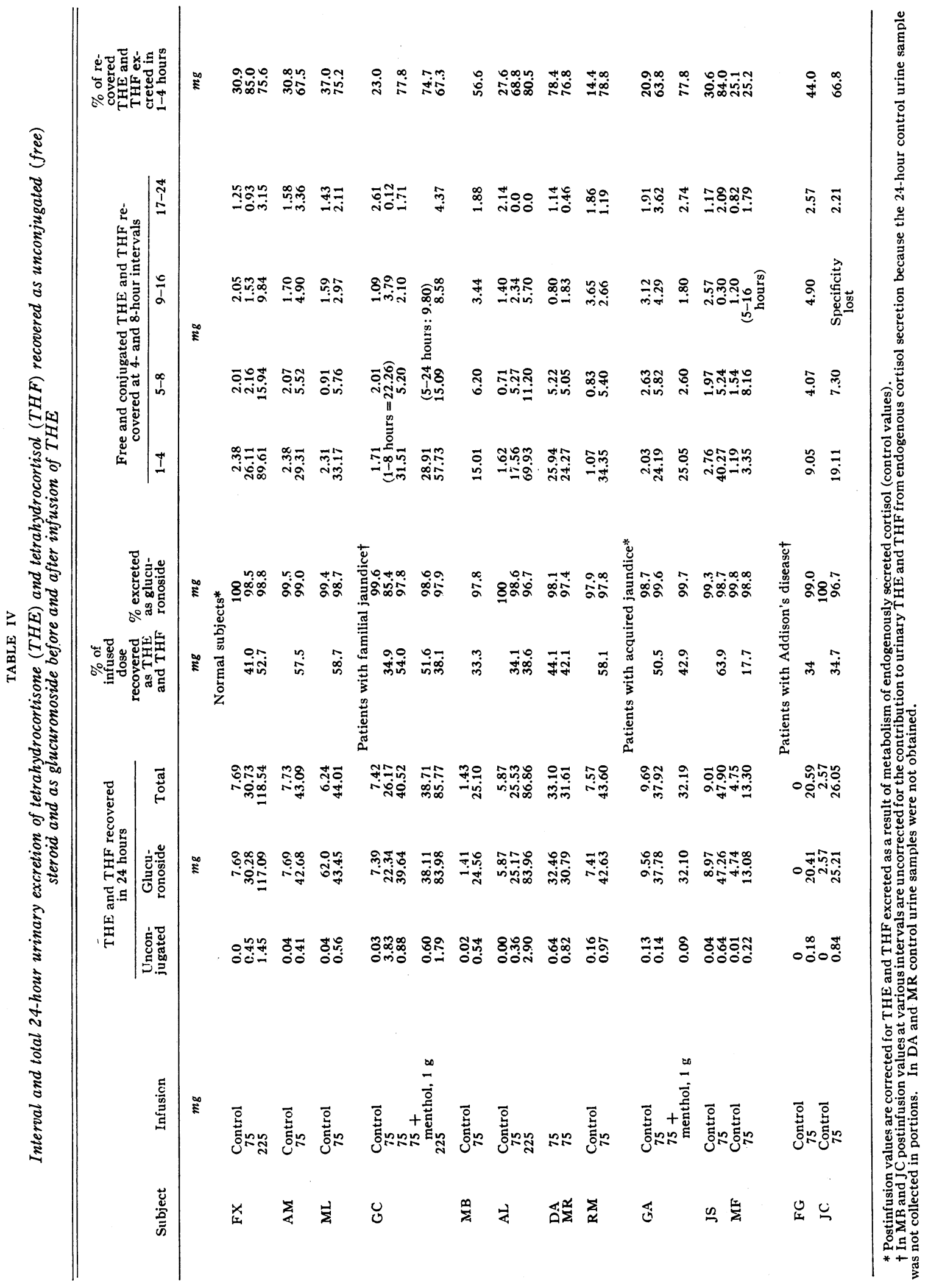


CONJUGATION OF STEROIDS IN JAUNDICE

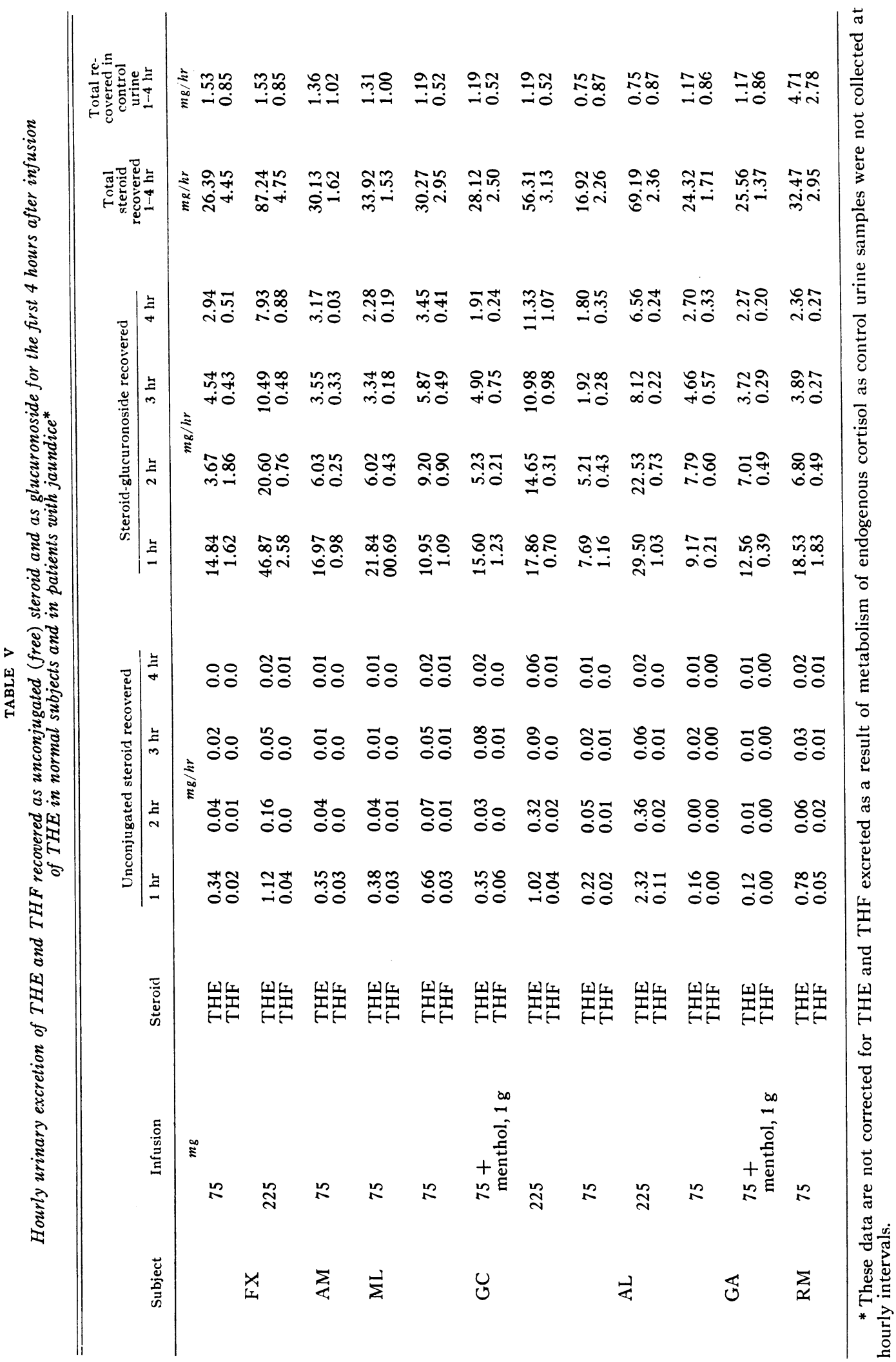


hours after infusion of $75 \mathrm{mg}$ of THE (67.5 to $85.0 \%$, Table IV). Seventy-five and six-tenths per cent of the metabolites recovered after the $225 \mathrm{mg}$ dose was excreted by FX in the first 4 hours (Table V). Table V and Figure 1 show that most of the urinary THE and THF appeared in the first hour following injection of THE, regardless of the size of the dose. There was a somewhat greater delay in the appearance of THF than of THE (Table V).

Patients with familial jaundice. In the first 4 hours after infusion of THE, $75 \mathrm{mg}$ and $225 \mathrm{mg}$, the patients with UDP-transglucuronylase deficiency excreted from 56.6 to $80.5 \%$ of the THE and THF eventually recovered in the urine by the end of 24 hours (Table IV). With the possible exception of $\mathrm{MB}$ (56.6\% excretion in the first 4 hours), these results are similar to those found in the normal subjects (67.5 to $85.0 \%$ ). The first time GC was studied when the plasma $t_{\frac{1}{2}}$ for the injected THE was prolonged, urine was collected at 8-hour intervals only. To detect early abnormalities in THE metabolism, urine was collected thereafter in 1-hour samples for the first
4 hours following the loading dose of THE (see below). The data for the first 4 hours (Table V, Figure 1) clearly show that there was a significant delay in the excretion of THE, a lesser amount of the steroid appearing in the first hour and a greater amount in the second hour than in the normal subjects. This phenomenon occurred at both dosage levels of THE.

When GC received oral menthol before the injection of $75 \mathrm{mg}$ THE, the per cent THE and THF excreted within the first and second hours returned to the normal pattern (Table V, Figure 2). Menthol conjugation remained impaired, the value being less than $50 \%$ of normal, a value essentially the same as that obtained when menthol was administered alone (Table I). This experiment is to be compared with that done in subject GA with a past history of viral hepatitis (see below).

The pattern of excretion of THF in the patients with familial jaundice followed that shown by the normal subjects (Table V). In AL, however, an abnormally large amount of THF appeared in the unconjugated fraction in the first

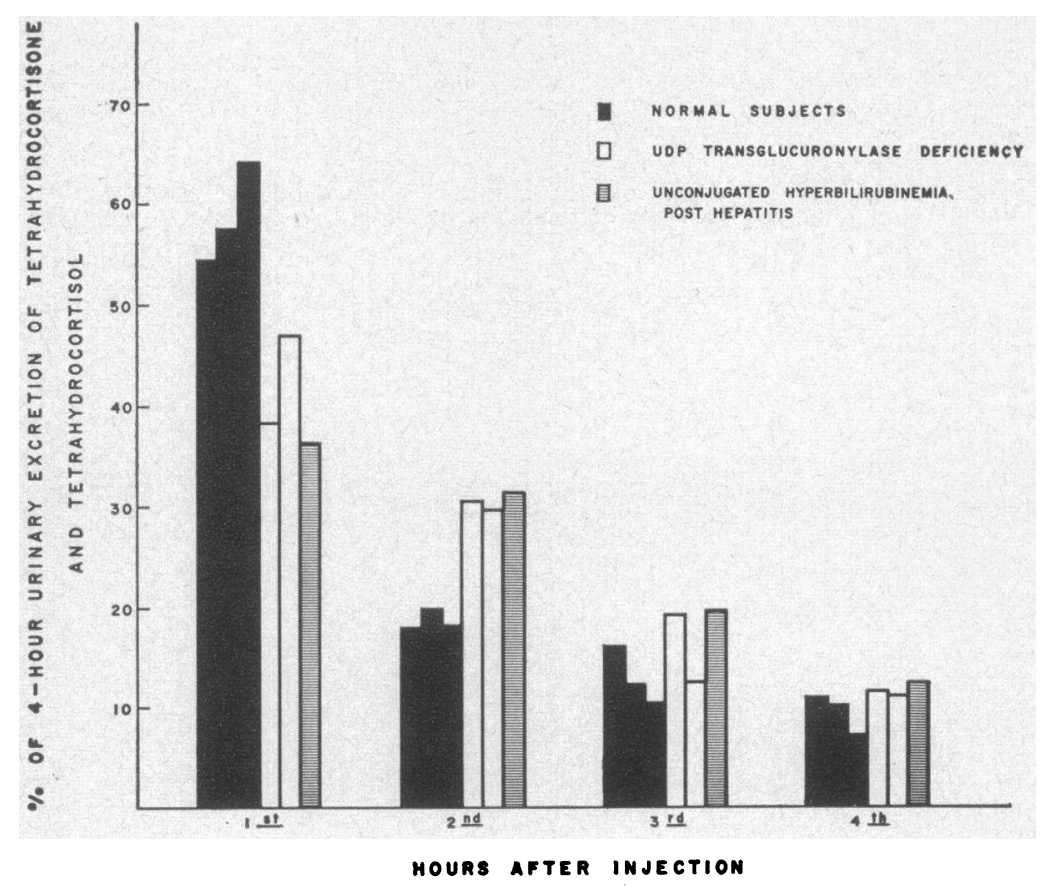

Fig. 1. Hourly eXCRETION OF TETRAHYDROCORTISONE (THE) AND TETRAHYDROCORTISOL (THF) DURING THE FIRST 4 HOURS AFTER INTRAVENOUS ADministration of THE, 75 mg. Data are expressed as per cent of THE and THF excreted in the 4-hour period. 


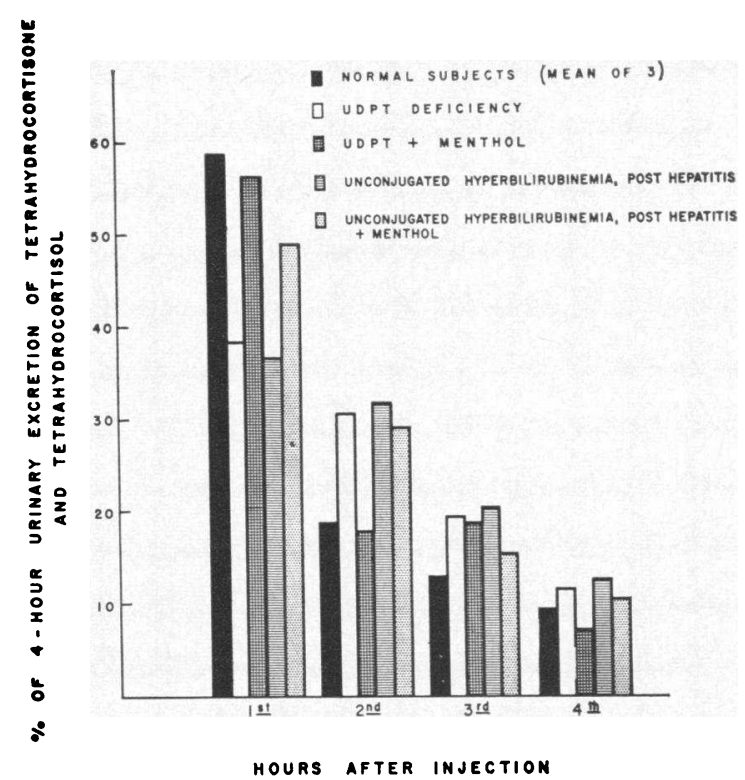

Fig. 2. Hourly excretion of THE and THF after INTRAVENOUS ADMINISTRATION OF THE, 75 MG, IN PATIENT GC WITH URIDINE DIPHOSPHATE TRANSGLUCURONYLASE (UDPT) DEFICIENCY AND PATIENT GA (PAST HisTORY OF HEPATITIS) COMPARED TO NORMAL SUBJECTS. Note that delay in steroid excretion is reduced when the same experiment is carried out after oral administration of menthol.

hour following administration of the larger loading dose of THE.

The two patients with the Dubin-Johnson syndrome excreted $78.4 \%$ (DA) and $76.7 \%$ (MR) of the recovered THE and THF within the first 4 hours (Table IV). In these two patients, urine was not collected at hourly intervals. RM, the patient with compensated hemolytic anemia metabolized THE normally (Tables IV and V). Of the THE and THF recovered in the first 4 hours, $59.5 \%$ was excreted during the first hour and only $21.2 \%$ in the second. The values do not differ from normal.

\section{Steroid metabolites recovered in urine after THE infusion}

History of hepatitis, fatty liver, and hepatic cirrhosis. GA, the patient with unconjugated hyperbilirubinemia and a past history of viral hepatitis, excreted $50.5 \%$ of the infused THE as THE and THF in 24 hours (Table IV). Of this, $4.2 \%$ was $\mathrm{THF}$ and only $0.4 \%$ was unconjugated (Table IV). In the first 4 hours after in- fusion, $63.8 \%$ of the recovered dose appeared (Table IV), a normal amount, but only $36.6 \%$ of this was excreted within the first hour, whereas $32.2 \%$ appeared in the second hour (Table V, Figure 1). This pattern is almost identical to that shown by GC (glucuronyl-transferase deficiency). Moreover, when oral menthol was ingested 2 hours before injection of THE, the THE and THF excreted within the first hour increased by $11.9 \%$ and that excreted in the second hour decreased by $4.4 \%$ (Table V, Figure 2 ), the total recovery at the end of 4 hours remaining unchanged (Table V).

JS (fatty infiltration and cellular necrosis) excreted $63.9 \%$ of administered THE as THE and THF in 24 hours (Table IV). Eighty-four per cent of the total 24-hour urinary excretion took place within the first 4 hours (Table IV), and $48.5 \%$ of that appeared within the first hour. Unconjugated THE and THF accounted for only $1.3 \%$ of the total recovered steroid (Table IV).

MF (advanced Laënnec's cirrhosis) excreted only $17.7 \%$ of the infused THE as THE and THF in 24 hours (Table IV), a subnormal amount. Of this steroid, $1.2 \%$ was unconjugated. In the first 4 hours following infusion, $3.35 \mathrm{mg}$ of THE and THF was recovered, $25.2 \%$ of the amount recovered in 24 hours (Table IV), again an abnormally low proportion. Thirty-two and four-tenths per cent of the first 4-hour excretion appeared in the first hour. Interconversion of THE to THF appeared to be unimpaired in this patient.

Addison's disease. The 24-hour recovery of THE and THF was normal in both patients, although JC appeared to excrete $3.3 \%{ }^{8}$ of the administered THE (75 $\mathrm{mg}$ ) as unconjugated steroid, a somewhat elevated value (Table IV).

In FG there was a delay in the excretion of metabolites as evidenced by a lesser per cent of re-

8 This high percentage of free steroid may be accounted for by the fact that the sample collected from hours 9 to 16 in this patient was lost (Table IV). A loss of steroid at this time with no loss during the first 4 hours, the period in which virtually all of the unconjugated metabolites appear, could easily result in a distortion of the true state of glucuroconjugation. For the same reasons, the figure of $66.8 \%$ for recovery of $\mathrm{THE}$ and THF in the first 4 hours (Table IV) is somewhat higher than it should be. 
covered THE and THF excreted within the first 4 hours (Table IV) and a greater per cent recovered in the second 8 hours than in any other patient. In neither patients JC nor FG did interconversion of $\mathrm{THE}$ to $\mathrm{THF}$ exceed the normal limits.

\section{Metabolism of cortisol}

All of the normal subjects except FX, and patients $\mathrm{GC}, \mathrm{AL}, \mathrm{DA}, \mathrm{JS}, \mathrm{MF}$, and GA received $100 \mathrm{mg}$ of cortisol. The excretion of urinary metabolites was studied in the same manner as for the THE experiments and included the collection of urine at hourly intervals for the first 4 hours. Although the appearance of THE and THF in the urine followed an entirely different pattern from that following THE, the only patient who showed deviation from the normal was MF (hepatic cirrhosis). In this patient total 24-hour recovery of steroid was reduced and its appearance in urine was delayed markedly.

\section{Discussion}

Metabolism of tetrahydrocortisone in normal subjects. The studies of normal subjects show that THE is rapidly conjugated with glucuronic acid and that the urinary excretion of this glucuronoside is also prompt. Within the limits tested, the dosage of administered THE does not appreciably influence its rate of metabolism. For cortisol, the rate of disappearance is slower after a pharmacologic dose than after a trace amount of radioactively labeled hormone (30). Although plasma disappearance rate of a trace quantity of THE has not been measured, Rappaport and Migeon (31) reported an average of $1.95 \%$ of nonconjugated radioactive label in urine of normal subjects after intravenous infusion of $4-\mathrm{C}^{14}-\mathrm{THF}$, a per cent comparable to that reported here for excretion of unconjugated THE and THF after much larger quantities of THE.

The metabolism of THF may not be entirely comparable to that of THE. The rate of appearance of THF glucuronoside was slower than that for THE, indicating that THF may be conjugated more slowly (data not shown here).

The recovery of THF after the injection of THE confirms the work of several authors concerning the interconversion of these two steroids
$(27,32,33)$. This transformation occurs rapidly (27). In the present study, increased amounts of THF were always recovered within the first hour after infusion of THE. C-20-reduced steroids, e.g., $\beta$-cortolone, were not specifically sought; others have shown rapid conversion of THE to this group of compounds $(27,32,33)$. The capacity to convert THE to THF is, however, limited. Only slightly greater amounts of THF were recovered after administration of $225 \mathrm{mg}$ of THE than after $75 \mathrm{mg}$. Steroid not recovered as urinary THE and THF after THE infusion was not identified in this investigation. In addition to C-20 hydroxylated derivatives, C-19, 11-oxygenated-17-ketosteroids are formed (2). On the second occasion that patient GC received an infusion of $75 \mathrm{mg}$ of THE, the 24-hour urinary excretion of 17-ketosteroids and 17-ketogenic steroids was measured and compared to control values: $40.5 \mathrm{mg}$ of THE plus THF were isolated; the 17ketogenic steroid excretion rose $42.2 \mathrm{mg}$. The closeness of these two figures indicates little, if any, significant conversion of THE to C-20 hydroxylated derivatives. 17-Ketosteroid excretion increased by $8.5 \mathrm{mg}$, a quantity representing only $11 \%$ of the administered THE, presumably converted to $\mathrm{C}-19$ compounds. The fate of a significant portion (about one-third) of the administered THE thus remains unaccounted for.

Metabolism of tetrahydrocortisone in patients with familial jaundice. Evidence for delayed metabolism of THE was found in all three patients with UDP-transglucuronylase deficiency, but not in those with familial jaundice of other etiology. In $\mathrm{MB}$, abnormal glucuroconjugation was shown by delay in plasma disappearance rate of THE. The small increase in per cent THE converted to THF may also have been the direct consequence of a slower rate of glucuronoside formation, more time being available for interconversion to proceed. The failure to find a greater than normal increase in unconjugated steroid in the urine in this patient may be attributable to renal insufficiency. MB suffered from chronic pyelonephritis (blood urea nitrogen, $49 \mathrm{mg}$ per $100 \mathrm{ml}$ ) and congestive heart failure. It is unlikely that renal disease accounts for the prolonged $t_{\frac{1}{2}}$ of unconjugated THE, however, since marked prolongation of plasma disappearance rate of cortisol is not characteristic of renal failure (34), and the rate 
of appearance of steroid glucuronosides in the plasma after cortisol infusion is not impaired (34). Thus, if steroid glucuronoside formation had been normal, plasma disappearance of unconjugated THE would probably have been normal also.

Impairment of steroid glucuronoside formation was easily demonstrable in GC during the first investigation of the patient. Plasma disappearance rate of administered THE was prolonged, and there was a great increase in unconjugated THE in the urine. When he was studied again 1 year later, the defect in steroid conjugation was quantitatively less striking. (The level of unconjugated bilirubin at this time was one-fourth that of the initial study.) He showed a reduced excretion of THE glucuronoside in the first hour relative to the second hour after administration of THE. Delay in plasma disappearance of THE was not found. Since urinary excretion of unconjugated steroid was not increased either, the capacity of the liver to take up free steroid must have been sufficient to prevent its accumulation in plasma. Measurement of plasma disappearance rate is therefore not suited to the detection of subtle deficiencies in the conjugating mechanism. Administration of triple the dose of THE failed to bring out the defect in GC with greater sharpness, but delay in the appearance of THE glucuronoside in the urine was again demonstrable. The findings in AL, who was also given both dosage levels of THE, were similar to those of GC when the latter was studied for the second time, but the deviation from normal was somewhat less marked.

Plasma disappearance rate of THE was not always abnormal; even when it was not, prolonged delay in excretion of THE glucuronoside in the first hour relative to its recovery in the second hour after THE infusion distinguished the above patients from the normal subjects and those with familial unconjugated hyperbilirubinemia who failed to demonstrate diminished tolerance for menthol, or in whom hepatic UDP-transglucuronylase activity was not demonstrably reduced by in vitro assay. Although this phenomenon appears to be limited to only a single group of patients with familial jaundice, the data in GA (unconjugated hyperbilirubinemia and past history of viral hepatitis) suggest that it may not be entirely specific. In this regard, a study made by Beck and Kuhn (35) may be pertinent.

These workers collected urine at three 3 -hour intervals to measure rate of excretion of menthol in patients with indirect hyperbilirubinemia. A diminished excretion of menthol glucuronoside in the first three hours after ingestion of $1 \mathrm{~g}$ of the compound was found. An increased amount of the conjugate appeared in the subsequent three hours compared to the findings in normal subjects. Thus, by the end of the collection period, total menthol glucuronoside excretion often fell within the normal range. The patients in that series (35) were not selected as to the etiology of the jaundice, and some individuals known to have hemolytic disorders also demonstrated this phenomenon. Thus, although the value of determining the rate of excretion of a substrate glucuronoside appears established for the detection of abnormalities in glucuronoside formation (in the absence of renal disease), abnormal findings may not necessarily indicate a specific fixed lesion.

Nevertheless, our observations in MB, GC, and $\mathrm{AL}$ are consistent with those of Arias and London (15) and Arias (16) and lead to the conclusion that certain patients with chronic unconjugated hyperbilirubinemia have a diminished ability to glucuroconjugate a variety of substrates. If but one glucuronoside conjugating mechanism exists, delay in THE glucuronoside formation was to be expected in MB, GC, and AL. Some data tend to support this notion. Glycosidic (steroid) and ester (bilirubin) UDP-transglucuronylase activities were not separable with a solubilized, partially purified preparation of UDP-transglucuronylase (36). In the homozygous Gunn rat, an animal with genetic deficiency of enzymes responsible for glucuronic acid transfer $(37,38)$, testosterone glucuronoside formation by everted intestinal sacs was impaired (39). To explain why the defect in steroid glucuronoside formation was quantitatively less striking than for bilirubin and menthol in $\mathrm{MB}, \mathrm{GC}$, and $\mathrm{AL}$, extrahepatic glucuroconjugation of steroid may be postulated. In vitro $(40,41)$ and in vivo $(42,43)$ experiments have demonstrated the capacity of kidney and gastrointestinal tract to carry out glucuronic acid conjugation. Alternatively, one may theorize that the affinity of the conjugating system for reduced steroid is greater than for the other substrates 
tested. In one experiment the rate of conjugation of THF was slower than that of THE, indicating that even small structural differences in substrates may be important. Other work has shown the importance of the $17 \alpha$-hydroxyl group in this regard (44). Another possible conclusion is that the enzyme system responsible for the glucuroconjugation of THE is different from the transferase necessary for bilirubin conjugation. In support of the idea that more than one glucuronic acid transferring enzyme may exist, Slaunwhite, Lichtman, and Sandberg (45) have demonstrated that glucuroconjugation at the 16 position of certain estrogenic hormones is accomplished in human liver by a system differing from that acting at the $3 \alpha$-position, the usual site of conjugation (2). Several investigators have also shown that $N$-linked glucuronosides are probably not dependent upon UDP-transglucuronylase $(46,47)$.

Detectable impairment of THE conjugation was abolished in GC when $1 \mathrm{~g}$ of menthol was administered 2 hours before the steroid. Although the conjugating defect in GC was shown to be variable (see above), and it may be argued that this finding was merely coincidental, indirect hyperbilirubinemia was present at the time of study, and impairment of menthol tolerance was as severe as it had been months earlier. Furthermore, this study was done only 9 days after a similar investigation without menthol administration had shown delay in steroid glucuronoside formation. The ability of menthol to favor more rapid appearance of THE glucuronoside in the urine after THE infusion was also demonstrable in subject GA (prior history of viral hepatitis). Possibly then, menthol can enhance the glucuroconjugation of THE in man. Although stimulation of hepatic microsomal enzyme activity by drugs has not been previously reported to occur in human subjects, its occurrence in experimental animals has been amply demonstrated (48-52). The apparent stimulation of THE conjugation by menthol in these experiments suggests that the transferase for THE glucuronoside formation may be distinct from that of menthol. Thus, the findings in the patients of this study cannot be attributed conclusively to a deficiency or a defect in a single conjugating enzyme.

Although others have postulated an abnormality in the hepatic uptake of substrate (53) in an unselected group with so-called "Gilbert's disease," this hypothesis does not fit the data of the present study. A defect in hepatic uptake of THE in our patients is most unlikely, since the conversion of THE to THF (an intracellular reaction) took place as readily and as rapidly in them as in the normal subjects. Although extrahepatic reduction of THE is, of course, a possible compensatory mechanism, its occurrence in man has not been demonstrated.

The present observations in adult patients with UDP-transglucuronylase deficiency are not entirely similar to those in children with a more severe form of unconjugated hyperbilirubinemia, the Crigler-Najjar syndrome (12). Whereas both rate of conjugation and total synthesis of steroid conjugate were impaired in the latter, only the rate of glucuronoside formation was diminished in the former. Detailed analysis of cortisol metabolism after $100 \mathrm{mg}$ of the hormone administered intravenously in the patients of this study failed to reveal any detectable abnormality. After cortisol-4-C ${ }^{14}$ was given to two children with the Crigler-Najjar syndrome, a subnormal quantity of injected radioactivity appeared in the urine in 24 hours as known metabolites [the majority of which should be C-21 glucuronosides (2) ], although total 24-hour urinary excretion of radioactivity appeared to be within the normal limits $(13,14)$. With the thought that a partial block in glucuronoside formation might result in utilization of an alternative pathway of cortisol metabolism not requiring conjugation for its urinary excretion, e.g., the formation of steroid not reduced in ring $A(25,54)$, urine was analyzed for $6 \beta$-hydroxycortisol ${ }^{9}$ before and after cortisol administration in two of the normal subjects, AM and AL, and in patient GC. The excretion of $6 \beta$-hydroxycortisol was normal in GC both before and after cortisol administration.

Metabolism of tetrahydrocortisone and cortisol in fatty liver and hepatic cirrhosis. Patient MF (advanced Laënnec's cirrhosis with hypersplenism and mild ascites) had an extremely disordered metabolism of both THE and cortisol. By contrast, patient JS with marked fatty infiltration of

9 These determinations were kindly made by Drs. Fred H. Katz and Marvin M. Lipman. 
the liver, inflammation, and early periportal fibrosis showed no derangement in the disposition of THE or cortisol. Most of the published reports $(30,55,56)$ concerning steroid metabolism in hepatic disease describe the patients studied as having Laënnec's cirrhosis without reference to specific cellular histology. From these data many generalizations about steroid metabolism in liver disease have been made. From these two patients alone, it is apparent that not all hepatic disorders which result in abnormal liver function cause steroidal abnormalities. More individualization of patients seems warranted.

The delay in plasma disappearance rate of cortisol in $\mathrm{MF}$ is in keeping with liver disease. Peterson has attributed this delay to a specific defect in the reduction of the 4,5 double bond of cortisol $(30,56,57)$. The small recovery of THE and THF 24 hours after cortisol infusion in MF suggests that more than a delay in ring-A reduction of the hormone was involved especially since recovery of steroid after THE infusion was similarly reduced. Because of ascites, steroid may have been distributed into ascitic fluid and its ultimate metabolism delayed $(55,56)$. Although disappearance rate of THE was normal in MF and has been found to be so in others with hepatic disease $(30,57)$, a defect in glucuronoside formation might still exist. Sequestration of unconjugated THE in an extravascular compartment could obscure a defect in glucuroconjugation by removing steroid from plasma at a rapid rate.

Whether the extremely low recovery of administered THE in MF indicates use of an alternative pathway of metabolism was not specifically investigated. In another patient with previously demonstrated UDP-transglucuronylase deficiency who subsequently developed severe cirrhosis of obscure etiology, equally poor recovery of THE after an infusion of $75 \mathrm{mg}$ THE was found. This patient did not have clinical ascites at the time of investigation. Details of this study are not presented because of the complex and ill-defined disorder of hepatic function. However, with Burstein and Lieberman's technique of solvolysis (58) after $\beta$-glucuronidase hydrolysis and ethyl acetate extraction of the urine as described in the section on methods, no sulfate conjugates of reduced steroid could be identified in a 24-hour sample of urine from this patient after THE in- fusion. This observation provides no support for sulfuric acid conjugation as an alternative metabolic pathway.

Metabolism of tetrahydrocortisone in patients with Addison's disease. THE infusion studies were made in patients with Addison's disease in order to test the possibility that prolonged absence of substrate might influence the ability of the organism to metabolize it. No evidence for this was observed. Delay in THE glucuronoside excretion in the first 4 hours after infusion in patient FG can be attributed to the hemodynamic alterations associated with untreated hypoadrenocorticism. The blood urea nitrogen in this patient was elevated $(41 \mathrm{mg}$ per $100 \mathrm{ml}$ ) at the time of study and returned to normal after cortisone replacement therapy was instituted. Thus, defect in glucuronoside formation need not be postulated.

\section{Summary}

1) After rapid intravenous administration of tetrahydrocortisone (THE), the rate of reduced steroid conjugation with glucuronic acid was assessed by measuring the rate of its plasma disappearance and by analyzing urine collected at frequent intervals after infusion. These procedures yielded useful information concerning steroid metabolism provided renal function was normal.

2) In three adult patients with familial jaundice previously shown to have hepatic deficiency of the enzyme uridine diphosphate (UDP)-transglucuronylase, but not in other patients with familial jaundice of differing etiology, THE glucuronoside formation was delayed without appreciable impairment in total synthesis. Quantitatively, the lesion was not so severe for steroid as it was for bilirubin and menthol. The metabolism of cortisol was normal. A delay in THE glucuronoside formation was also found in one subject with unconjugated hyperbilirubinemia and a past history of viral hepatitis.

3) In one patient with UDP-transglucuronylase deficiency the defect in THE conjugation could not be detected after $1 \mathrm{~g}$ of menthol was administered 2 hours before a test dose of THE. In the patient with a past history of hepatitis the same dose of menthol also enhanced the rate of THE glucuronoside formation. This and other data suggest that the transferase for THE glu- 
curonoside formation may be distinct from that of menthol.

4) Two patients with severe hepatic insufficiency secondary to alcoholism but differing in their clinical and pathological findings were studied. One showed a severe disorder of both THE and cortisol metabolism, and the other did not. Thus patients with even marked impairment of liver function do not comprise a homogeneous group with respect to the disposition of steroid hormones.

5) In two patients with untreated Addison's disease, the metabolism of THE was essentially normal. Prolonged absence of normal amounts of substrate therefore does not affect the ability to metabolize it.

\section{References}

1. Williams, R. T. Detoxication Mechanisms, 2nd ed. London, Chapman and Hall, 1959, chap. 1.

2. Samuels, L. T. Metabolism of steroid hormones in Chemical Pathways of Metabolism, D. M. Greenberg, Ed. New York, Academic Press, 1960, vol. 1, p. 431.

3. Fukushima, D. K., N. S. Leeds, H. L. Bradlow, T. H. Kritchevsky, M. B. Stokem, and T. F. Gallagher. The characterization of four new metabolites of adrenocortical hormones. J. biol. Chem. 1955, 212, 449.

4. Schneider, John J., M. L. Lewbart, P. Levitan, and S. Lieberman. Isolation from urine and synthesis of tetrahydrocortisone glucuronoside. J. Amer. chem. Soc. 1955, 77, 4184.

5. Daughaday, W. H., and R. Bremer. The association of $17-\mathrm{OH}$ corticosteroids and $17-\mathrm{OH}$ corticosteroid glucuronides with plasma proteins and the mechanisms of corticosteroid excretion. J. Lab. clin. Med. 1955, 46, 807.

6. Sandberg, A. A., W. R. Slaunwhite, Jr., and H. N. Antoniades. The binding of steroids and steroid conjugates to human plasma proteins. Recent Progr. Hormone Res. 1957, 13, 209.

7. Dutton, G. J. The mechanism of glucuronide formation. Biochem. Pharmacol. 1961, 6, 65.

8. Isselbacher, K. J., and J. Axelrod. Enzymatic formation of corticosteroid glucuronides. J. Amer. chem. Soc. 1955, 77, 1070.

9. Isselbacher, K. J. Enzymatic mechanisms of hormone metabolism II. Recent Progr. Hormone Res. 1956, 12, 134.

10. Billing, B. H., P. G. Cole, and G. H. Lathe. The excretion of bilirubin as a diglucuronide giving the direct van den Bergh reaction. Biochem. J. 1957, 65, 774.

11. Schmid, R. Direct-reacting bilirubin, bilirubin glucuronide, in serum, bile and urine. Science 1956, 124, 76.
12. Crigler, J. F., Jr., and V. A. Najjar. Congenital familial nonhemolytic jaundice with kernicterus. Pediatrics 1952, 10, 169.

13. Peterson, R. E., and R. Schmid. A clinical syndrome associated with a defect in steroid glucuronide formation. J. clin. Endocr. 1957, 17, 1485.

14. Childs, B., J. B. Sidbury, and C. J. Migeon. Glucuronic acid conjugation by patients with familial nonhemolytic jaundice and their relatives. Pediatrics 1959, 23, 903.

15. Arias, I. M., and I. M. London. Bilirubin glucuronide formation in vitro; demonstration of a defect in Gilbert's disease. Science 1957, 126, 563.

16. Arias, I. M. Chronic unconjugated hyperbilirubinemia without overt signs of hemolysis in adolescents and adults. J. clin. Invest. 1962, 41, 2233.

17. Dubin, I. N., and F. B. Johnson. Chronic idiopathic jaundice with unidentified pigment in liver cells: new clinicopathologic entity with report of 12 cases. Medicine (Baltimore) 1954, 33, 155.

18. Mollison, P. L., and N. Veall. The use of isotope ${ }^{51} \mathrm{Cr}$ as a label for red cells. Brit. J. Haemat. 1955, $1,62$.

19. Watson, C. J., S. Schwartz, V. Sborov, and E. Bertie. Studies of urobilinogen. V. A simple method for quantitative recording of Ehrlich reaction as carried out with urine and feces. Amer. J. clin. Path. 1944, 14, 605.

20. Bush, I. E. Methods of paper chromatography of steroids applicable to the study of steroids in mammalian blood and tissues. Biochem. J. 1952, 50, 370.

21. Eberlein, W. R., and A. M. Bongiovanni. New solvent systems for the resolution of corticosteroids by paper chromatography. Arch. Biochem. 1955, 59, 90.

22. Silber, R. H., and C. C. Porter. The determination of 17,21-dihydroxy-20-ketosteroids in urine and plasma. J. biol. Chem. 1954, 210, 923.

23. Peterson, R. E., A. Karrer, and S. L. Guerra. Evaluation of Silber-Porter procedure for determination of plasma hydrocortisone. Analyt. Chem. 1957, 29, 144.

24. Christy, N. P., D. Longson, W. A. Horwitz, and M. M. Knight. Inhibitory effect of chlorpromazine upon the adrenal cortical response to insulin hypoglycemia in man. J. clin. Invest. 1957, 36, 543.

25. Frantz, A. G., F. H. Katz, and J. W. Jailer. $6 \beta-\mathrm{Hy}-$ droxycortisol and other polar corticosteroids: measurement and significance in human urine. $\mathrm{J}$. clin. Endocr. 1961, 21, 1290.

26. Roginsky, M. S., W. D. Drucker, and N. P. Christy. Partition of 17,21-dihydroxy-20-ketosteroids in various solvent pairs. Fed. Proc. 1963, 22 (no. 2, part 1), 165.

27. Gold, N. I., L. L. Smith, and F. D. Moore. Cortisol metabolism in man: observations of pathways, pool sizes of metabolites and rates of formation of metabolites. J. clin. Invest. 1959, 38, 2238. 
28. Allen, W. M. A simple method for analyzing complicated absorption curves, of use in the colorimetric determination of urinary steroids. J. clin. Endocr. 1950, 10, 71.

29. Silber, R. H., and C. C. Porter. Determination of 17,21-dihydroxy-20-ketosteroids in urine and plasma. Meth. biochem. Anal. 1957, 4, 139.

30. Peterson, R. E. Adrenocortical steroid metabolism and adrenal cortical function in liver disease. $\mathrm{J}$. clin. Invest. 1960, 39, 320.

31. Rappaport, R., and C. J. Migeon. Physiologic disposition of $4-\mathrm{C}^{\mathbf{1 4}}$-tetrahydrocortisol in man. J. clin. Endocr. 1962, 22, 1065.

32. Savard, K., and S. H. Goldfaden. Metabolism of pregnane-11 $\beta, 17 \alpha, 21$-triol-3, 20-dione (dihydro compound $\mathrm{F}$ ) and pregnane- $3 \alpha, 11 \beta, 17 \alpha, 21$-tetrol20-one (tetrahydro compound $F$ ) in human subjects. Fed. Proc. 1954, 13, 288.

33. Peterson, R. E., C. E. Pierce, J. B. Wyngaarden, J. J. Bunim, and B. B. Brodie. The physiological disposition and metabolic fate of cortisone in man. J. clin. Invest. 1957, 36, 1301.

34. Englert, E., Jr., H. Brown, D. G. Willardson, S. Wallach, and E. L. Simons. Metabolism of free and conjugated 17-hydroxycorticosteroids in subjects with uremia. J. clin. Endocr. 1958, 18, 36.

35. Beck, K., and H. A. Kuhn. Beitrag zur Pathogenese der funktionellen Hyperbilirubinämie. Z. klin. Med. 1959, 155, 547.

36. Isselbacher, K. J., M. F. Chrabas, and R. C. Quinn. The stabilization and partial purification of a glucuronyl transferase from rabbit liver microsomes. J. biol. Chem. 1962, 10, 3033.

37. Gunn, C. K. Hereditary acholuric jaundice. J. Hered. 1938, 29, 137.

38. Axelrod, J., R. Schmid, and L. Haymaker. A biochemical lesion in congenital, non-obstructive, nonhemolytic jaundice. Nature (Lond.) 1957, 180, 1426.

39. Arias, I. M., M. Furman, D. F. Tapley, and J. E. Ross. Glucuronide formation and transport of various compounds by Gunn rat intestine in vitro. Nature (Lond.) 1963, 197, 1109.

40. Stevens, W., D. L. Berliner, and T. F. Dougherty. Conjugation of steroids by liver, kidney and intestine of mice. Endocrinology 1961, 68, 875.

41. Berliner, D. L., and T. F. Dougherty. Hepatic and extrahepatic regulation of corticosteroids. Pharmacol. Rev. 1961, 13, 329.

42. Cohn, G. L., and M. Hume. The in vivo glucuronide conjugation of radioactive etiocholanolone and androsterone by the dog kidney. J. clin. Invest. 1960, 39, 1584.

43. Diczfalusy, E., G. Franksson, B. P. Lisboa, and B. Martinson. Formation of oestrone glucosiduronate by the human intestinal tract. Acta endocr. (Kbh.) 1962, 40, 537.
44. Berliner, D. L., W. Stevens, and T. F. Dougherty. Influence of steroidal structure on glucuronoside formation by mouse liver and kidney. Proc. Soc. exp. Biol. (N. Y.) 1962, 110, 268.

45. Slaunwhite, W. R., A. M. Lichtman, and A. A. Sandberg. Biosynthesis of estriol-16 $\alpha$-glucosiduronic acid-16-C $\mathrm{C}^{14}$ in Proc. 44th Meeting Endocrine Soc. 1962, p. 8.

46. Arias, I. M. Ethereal and $N$-linked glucuronide formation by normal and Gunn rats in vitro and in vivo. Biochem. biophys. Res. Commun. 1961, 6, 81.

47. Van Leusden, H. A. I. M., J. A. J. M. Bakkeren, F. Zilliken, and L. A. M. Stolte. P-Nitrophenylglucuronide formation by homozygous adult Gunn rats Biochem. biophys. res. Commun. 1962, 7, 67.

48. Conney, A. H., E. C. Miller, and J. A. Miller. The metabolism of methylated aminoazo dyes. V. Evidence for induction of enzyme synthesis in the rat by 3-methylcholanthrene. Cancer Res. 1956, 16, 450.

49. Inscoe, J. K., and J. Axelrod. Some factors affecting glucuronide formation in vitro. J. Pharmacol. exp. Ther. 1960, 129, 128.

50. Conney, A. H., E. C. Miller, and J. A. Miller. Substrate-induced synthesis and other properties of benzpyrene hydroxylase in rat liver. J. biol. Chem. 1957, 228, 753.

51. Dutton, G. J., and I. H. Stevenson. The stimulation by 3,4-benzpyrene of glucuronide synthesis in skin. Biochim. biophys. Acta (Amst.) 1962, 58, 633.

52. Arias, I. M., L. Gartner, M. Furman, and S. Wolfson. Effect of several drugs and chemicals on hepatic glucuronide formation in newborn rats. Proc. Soc. exp. Biol. (N. Y.) 1963, 112, 1037.

53. Galambos, J. T., and J. R. McLaren. Hepatic uptake defect in patients with "Gilbert's disease." Arch. intern. Med. 1963, 111, 214.

54. Burstein, S., R. I. Dorfman, and E. M. Nadel. $6 \beta-$ Hydroxycortisol-a new steroid in human urine. Arch. Biochem. 1956, 61, 144.

55. Brown, H., D. G. Willardson, L. T. Samuels, and F. H. Tyler. 17-Hydroxycorticosteroid metabolism in liver disease. J. clin. Invest. 1954, 33, 1524.

56. Englert, E., Jr., H. Brown, S. Wallach, and E. L. Simons. Metabolism of free and conjugated 17hydroxycorticosteroids in subjects with liver disease. J. clin. Endocr. 1957, 17, 1395.

57. Christy, N. P., E. Z. Wallace, W. E. L. Gordon, and J. W. Jailer. On the rate of hydrocortisone clearance from plasma in pregnant women and in patients with Laennec's cirrhosis. J. clin. Invest. 1959, 38, 299.

58. Burstein, S., and S. Lieberman. Hydrolysis of ketosteroid hydrogen sulfates by solvolysis procedures. J. biol. Chem. 1958, 233, 331. 